\title{
Sport for All Frail Bodies
}

Authors' contribution:

F) conception and design of the study

G) acquisition of data

H) analysis and interpretation of data

I) manuscript preparation

J) obtaining funding

\section{Ejgil Jespersen}

University of Southern Denmark, Denmark

\section{KEYWORDS}

\begin{abstract}
Sport for All is a universal Olympic idea adopted by supranational institutions such as the Council of Europe, UNESCO, and the UN. Measures that need to be taken to ensure that all people have an equal opportunity to be included in sport are analyzed and discussed based upon a survey of sports and exercise participation in Denmark with a special focus upon people with impairments. The prevailing point of view is a special needs approach to sports participation, whether it is oriented towards separate or integrated forms of organization. It is often unclear whether this approach is aiming for equality of outcome, equality of chance or just a minimum threshold for sports and exercise activity. However, if we adopt a universal approach to Sport for all, then the focus is not on differences among people, but upon the commonalities among human beings in light of their diversity. This approach is associated with the understanding of "universal design" in the UN's Convention of the Rights of Persons with Disabilities and the WHO's International Classification of Functioning, Disability, and Health. In conclusion, it is highlighted that a more inclusive Sport for All movement is preferable to a segregated or integrated disability sport, provided the persons concerned have a say in every case.

sport for all, special needs, universal design, human rights
\end{abstract}

\section{Sport for All Bodies: A universal vs. a special needs approach to sports participation}

Sport for All is an idea launched by Pierre de Coubertin (1967) as being the fulfillment of the doctrine of olympism, whereas the Olympic Games primarily serve as an instrument for the popularization of sports. Since 1966, when the term "Sport for All" was adopted by the Council of Europe (1970) to describe one of its long-term objectives, the Sport for All idea has gained the support of UNESCO (1978) and, recently, the United Nations Office on Sport for Development and Peace (SDP IWG, 2008).

While sport certainly is an arena for making a difference in equality, the idea of Sport for All is less clear. In one sense, it may express a universal approach to sports participation without any focus on special target groups. In another sense, if one stresses the differences or inequalities from the beginning in order to achieve an equal level of participation in the end, then the focus is in fact not on inclusive Sport for All. Instead, it becomes a question of studying the level of sports participation among supposedly disadvantaged groups of people and offering advice and guidance for promoting greater participation among those subgroups.

In this article, I focus on people who are disabled due to some kind of impairment. This is a special needs approach to sports participation, whether it is oriented towards separate or integrated forms of 
organization. The target group is, in both cases, people with impairments, and the aim is to enhance the accessibility of sport.

However, if we adopt a universal approach to Sport for All, then the focus from the beginning is not on differences among people, but upon the commonalities among human beings in light of their diversity. This approach is associated with the understanding of "universal design" in the UN's Convention of the Rights of Persons with Disabilities (2006):

“'Universal design' means the design of products, environments, programmes and services to be usable by all people, to the greatest extent possible, without the need for adaptation or specialized design. 'Universal design' shall not exclude assistive devices for particular groups of persons with disabilities where this is needed".

"Universal design" is a new concept in the Convention context. Universal design is a design that can be used by everyone, not just by people with disabilities. Universal design is a design that reflects society's diversity and the idea that all people should have an equal opportunity to be included in society. Universal design is not the same as the concept of accessibility. Universal design is targeted at all people, while accessibility is mainly targeted at people with disabilities.

Likewise, a universal approach to sport participation is giving priority in Article 30 of the Disability Convention (2006):

"With a view to enabling persons with disabilities to participate on an equal basis with others in recreational, leisure and sporting activities, States Parties shall take appropriate measures:

a) To encourage and promote the participation, to the fullest extent possible of persons with disabilities in mainstream sporting activities at all levels;

b) To ensure that persons with disabilities have an opportunity to organize, develop and participate in disability-specific sporting and recreational activities and, to this end, encourage the provision, on an equal basis with others, of appropriate instruction, training and resources".

In what follows, I refer to some data on sports participation in Denmark among persons with and without impairments and reflect upon the measures that need to be taken to ensure that all people have an equal opportunity to be included in sport.

\section{Method}

The data on sport participation is based upon a large survey called Shield (Survey of Health, Impairment, and Living Conditions in Denmark). The survey was conducted from October 2012 to February 2013, mainly in the form of web surveys and supplemented by telephone interviews. In both cases, respondents answered an extensive questionnaire concerning issues of impairments and participation in sport and exercise in general, and in sport clubs in particular. A random sample of 32,810 adult Danes aged 16 to 64 was extracted from the Population Register, and 18,957 answered the questionnaire, corresponding to a response rate of 58 percent.

A higher degree of representativeness was ensured by weighting data at a number of known parameters (gender, age, region of residence, and income). Even after weighting, there is still an overrepresentation of unemployed persons and persons with higher education. In addition, an underrepresentation of individuals who suffer from severe disabilities in terms of learning problems, brain damage, and some chronic mental disorders is also apparent. Nevertheless, the sample is considered fairly representative according to SFI, the Danish National Centre for Social Research (Damgaard et al., 2013). 


\section{Types of impairments}

The types of impairments in question are of diagnostic origin in terms of long-term physical impairment, physical health problems, and mental health problems. By using the general term of impairment, it is emphasized that some kind of activity limitation or participation restriction is experienced. However, the term impairment is also broader in scope than within the disability sport organization and in everyday speech, where disability is predominantly associated with physical defects.

Three groups of people with impairments are constructed based on these two questions:

1. Do you have a long-term physical health problem or disability? Is it a minor health problem or a major health problem? What is your most serious physical health problem or disability? This should be answered in relation to the following 19 types of health problems or disabilities (and in what follows, we distinguish between physical health problems and physical defects).

2. Do you have one or more mental disorders? Is it a minor mental disorder or a major psychiatric disorder? What is your most serious mental disorder? This should be answered in relation to the following nine types of mental disorders.

Here is a brief overview of the types of disabilities that are part of the three main groups:

1. A long-term physical disability: Includes those who have linked their serious physical health problems or disability problems with the arms or hands, problems with legs or feet, trouble with back or neck, blindness or visual impairment, deafness and impaired hearing, speech difficulties, cognitive developmental disabilities, Cerebral Palsy, spasticity, brain damage, or dyslexia.

2. A long-term physical health problem: Includes those who have linked their serious physical health problem or disability with skin disease, allergies, respiratory problems, problems with the heart, blood pressure, or circulation, problems with the stomach, liver, kidneys, or digestion, diabetes, epilepsy, and other progressive diseases such as cancer, multiple sclerosis, HIV, and Parkinson's disease.

3. Mental health problem: Includes people who have connected their serious mental disorder with the use of alcohol or drugs as a cause of the disorder, hearing voices, schizophrenia and psychosis, depression, mania and bipolar disorder, stress, phobias, various forms of anxiety, OCD, and posttraumatic stress disorder (PTSD), personality disorders including borderline, autism, Asperger's syndrome, ADHD, ADD, eating disorders, or other mental disorders.

A long-term physical disability is the most common form of impairment. Fourteen percent of the adult population, corresponding to around 400,000 people, report having a physical disability, although this is a minor disability for the majority (nine percent). In addition, nine percent, or about 250,000 people, report having a long-term physical health problem. Most of them (six percent) have a minor health problem. There is no overlap between physical disabilities and health problems in the study because the distinction was not originally made in the questionnaire.

There are, finally, nine percent, or about 250,000 people, who report that they have one or more mental disorders. For the most part (six percent), it is a minor mental disorder. In this case, there is an overlap between physical disabilities and health problems on the one side and mental health problems on the other. More than three percent, corresponding to about 98,000 people, have both physical and mental difficulties, but this is not an issue being addressed in this paper.

\section{Sports and exercise participation and impairment}

There is a strong correlation between sports and exercise participation and impairment in the sense that people with impairments are less active than people without impairments. This applies to all three main groups of impairments as well as the degree of impairment, so people with greater physical impairments and physical or mental health problems are the least active groups. 
As shown in Figure 1, eight out of ten people without impairments participate in sports or exercise, while roughly three out of four with minor impairments are active in sports or exercise. That figure drops to just over six out of ten when it comes to people with major impairments.

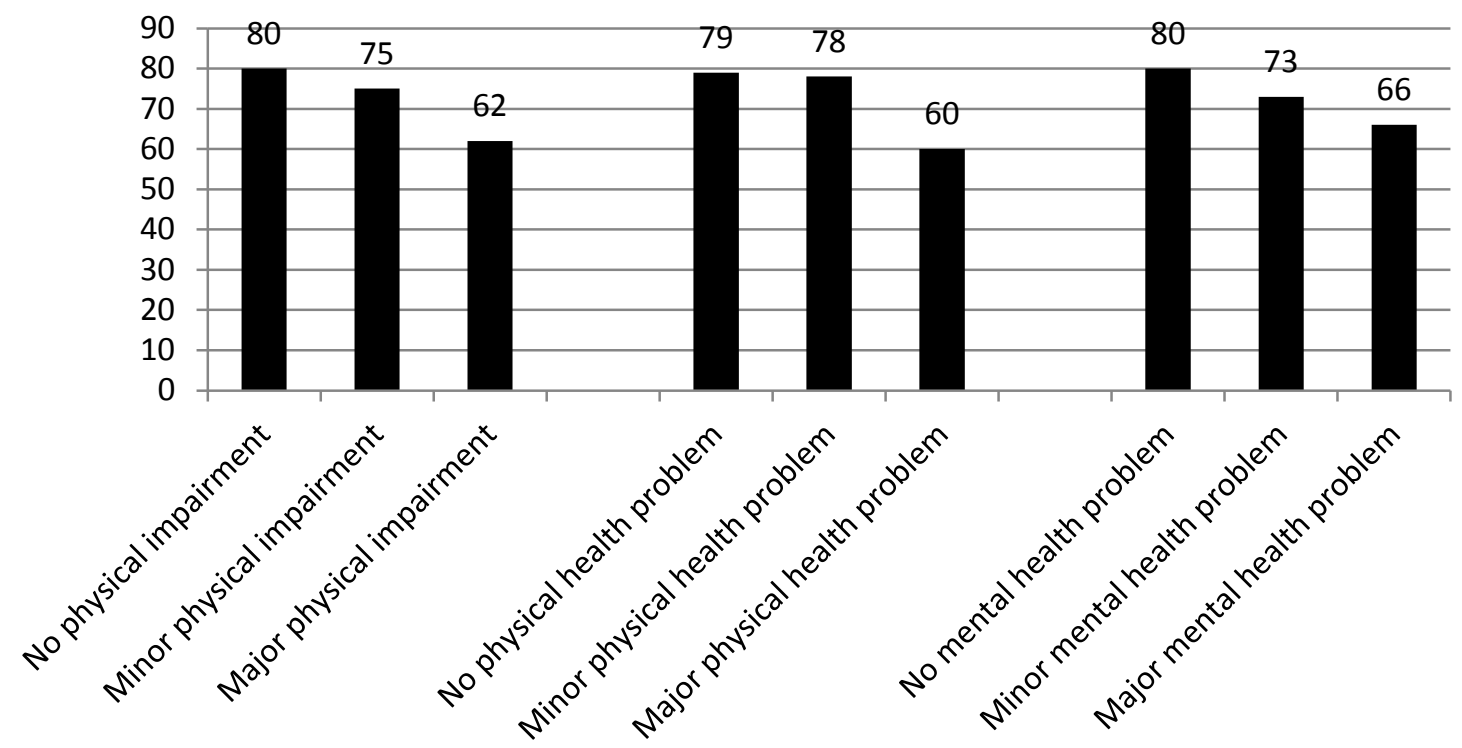

Figure 1. Proportion of people who practice sports or exercise, distributed by the type and degree of impairment (percent)

In light of the principle of equal participation levels in sport and exercise, it thus appears that people with impairments are under-represented among participants in sport and exercise, or, in other words, there is an inequality in the participation level. Other studies on the connection between physical activity and disability show similar results (Martin, 2013; Rimmer, Braddock \& Pitetti, 1996).

If a political goal of equality of outcome is to be achieved, then the proportion of people with impairments who participate in sports and exercise has to be raised to the standard level of participation among people without impairments. In this case, we are talking about 79,000 people with impairments, including 38,000 with physical impairments, 17,000 with physical health problems, and 24,000 with mental health problems. The 79,000 people with impairments constitute less than 13 percent of the nearly 625,000 adults aged 16-64 who remain inactive in sports or exercise, i.e., inactivity in sports and exercise is mostly dependent on factors other than impairment.

Figure 2 shows how the strong correlation between physical activity and impairment recurs in all three contexts of sports practice in sports clubs. Only about one in five with a major physical impairment, a major physical health problem, or a major mental health problem practices sport in a sports club, opposed to two out of five without impairments. Three out of five with minor mental health problems practice sport, while people with minor physical impairments or minor physical health problems are approaching the level of people without impairments who practice sport in sport clubs. 


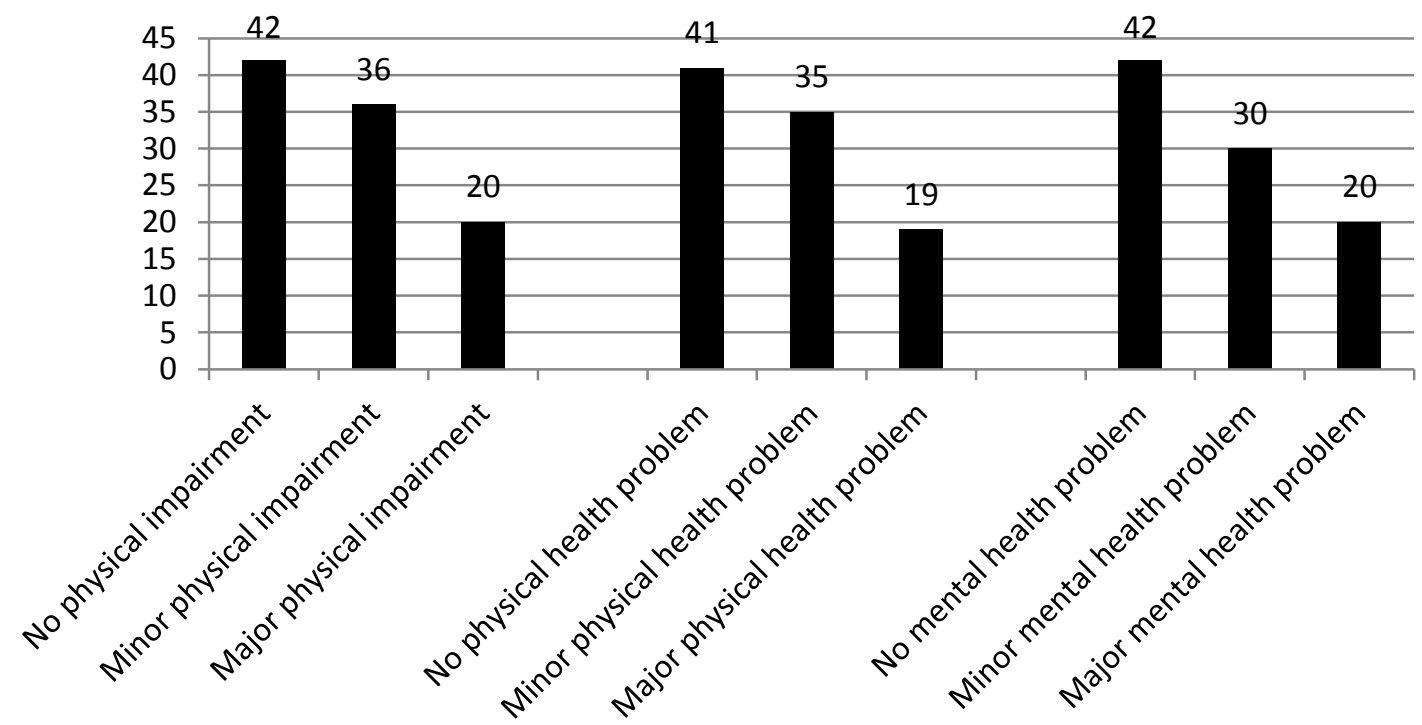

Figure 2. Proportion of people who practice sports in a sports club, distributed by the type and degree of impairment (percent)

If all three groups of people with impairments should achieve the level of people without impairments who practice sport in sport clubs, then there is a need to include 114,000 people: 47,000 with physical impairments, 28,000 with physical health problems, and 39,000 with mental health problems.

The standardization of the level of practicing sports and exercise in general and in sport clubs in particular among people with impairments is an instrument for a political goal to achieve some kind of equality. However, it is certainly not always clear whether this is a question of equality of outcome or, rather, equality of chance, or just a minimum threshold for the practice of sports and exercise.

When focusing upon equality of outcome, one may recall Procrustes from Greek mythology. He was a rogue smith and bandit from Attica who physically attacked people by stretching them or cutting off their legs, so as to force them to fit the size of an iron bed, later named "Procrustes' bed". All bodies of different lengths, sizes, and properties were to fit an arbitrary standard from the slogan "one-size-fits-all". Not many people survived this treatment, but equality of outcome was achieved.

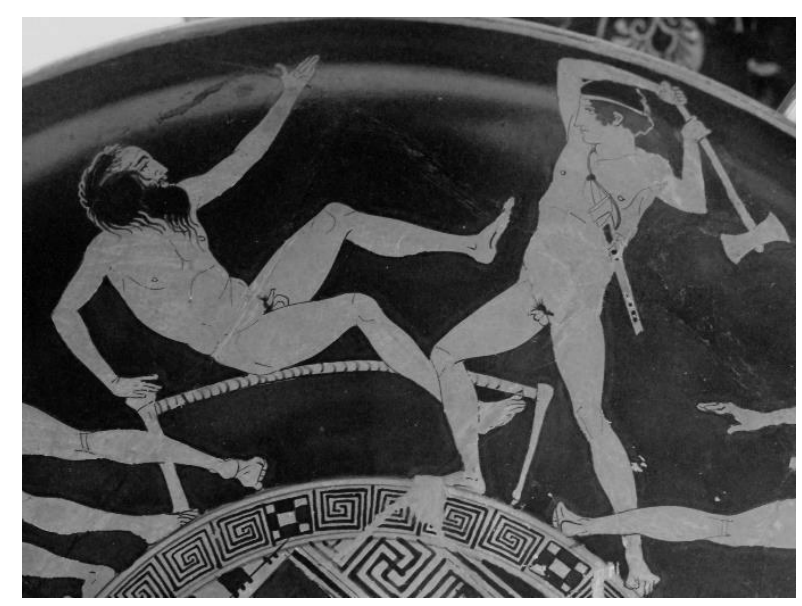

Procrustes continued his reign of terror until he was captured by Theseus, who "fit" Procrustes to his own bed and killed him.

The American author Kurt Vonnegut has updated Procrustes' myth in the short story "Harrison Bergeron" (Vonnegut, 1961). He describes - satirically - authoritarian dystopias of egalitarian policies involving socially enforced equality and, more specifically, enforcing equality by virtue of levelling. To 
achieve equality, all intelligent people weare a "mental handicap" radio jamming that prevents any complicated thought. Excellent ballet dancers must dance with sash weight, and the beautiful must wear masks, all in the name of equality of outcome.

The sport world is also close to the idea of equality of outcome. That is why talented contestants have been handicapped in order to make the competition equal in modern sports (Hansen,2015, pp. 7-13). In the end, however, there has to be an uncertainty about the outcome in order to maintain a different idea of equality, namely equality of chance, and offer an opportunity to make a difference. This is also why matchfixing is threatening the integrity of sport.

When politicians and scientists talk about equality of outcome as an ideal for sports participation with a special view to level the differences in the participation level among groups of people, they are in fact more often talking about two other norms, namely equality of chance and a minimum threshold for physical activity.

Sport for All may be pursued by promoting physical activity for all groups of people who are not yet active in sports and exercise. However, it seems to be more important to stress the idea that everyone should have the same chance in sports and physical activity, regardless of social background variables like income, education, ethnicity, and conditions like age, gender, and ability.

In the case of ability versus disability, it is sometimes difficult to maintain an idea of full and effective participation in sports and exercise on an equal basis with others in terms of inclusion, where all are equal and all are different. That is why people with impairments are excluded from sports clubs, or practice sport in separated, disability-specific sport clubs, or are integrated in disability-specific groups in mainstream sport clubs.

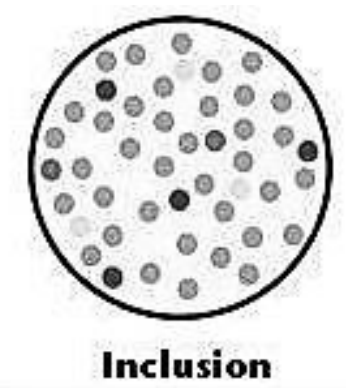

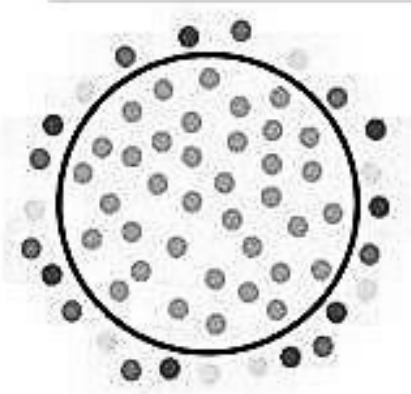

Exclusion

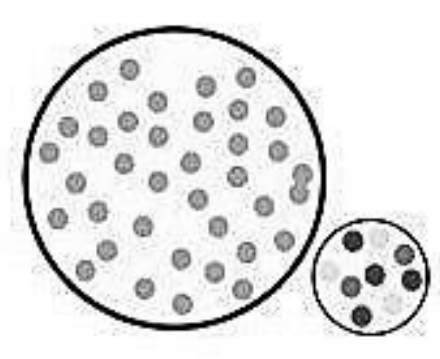

Segregation

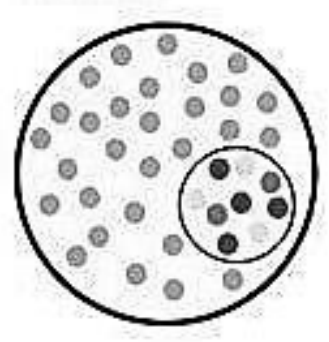

Integration

Being excluded from sports and exercise participation is bad from the perspective of Sport for All. Those who want to be involved in some sports setting should not be denied the opportunity simply because of an impairment or disability. Therefore, local sport clubs where people with impairments can participate on their own terms are a progressive step away from exclusion.

However, due to conditions of fair competition within the disability sport and Paralympic movement, the participants need to be identified with eligible impairments for a particular sport, and, furthermore, the 
methods for the assessment of athletes must be based on specific evidence so that the impact of the impairment on the activity is proven (Tweedy \& Vanlandewijk, 2011).

In this way, disability sport is strictly separated from mainstream sport and does not have anything to do with integration or inclusion in the Sport for All movement. Special schools and settlements or institutions for people with impairments are similar examples of segregated solutions. These measures, which value the right to life of disabled people, are, of course, preferable to the disregard of disabled people. However, being placed in any form of segregated setting tends to force disabled people to lead a separate or parallel life.

That is why it is preferable to integrate and include people with impairments to the fullest extent possible in mainstream sporting activities at all levels. When people are integrated in mainstream sport settings with some adaptations and, possibly, resources, it is expected that they can fit in with pre-existing structures, attitudes, and an unaltered environment. However, they are still labeled as people with impairments. Only where there is a commitment to removing all barriers to the full participation of everyone as equally valued and unique individuals, and where all participants feel welcome, accepted, safe, and confident, is a sport practice entitled to be labeled as inclusive and associated with equal opportunities and the Sport for All movement.

An important task for research in sport and exercise participation is how we measure such equality of opportunity in a world with huge political and cultural differences. Sometimes the study, as in the abovementioned case, is restricted to comparing the level of sport and exercise participation among people with and without impairments. At other times, the study simply measures how many people are meeting certain standards of prescribed exercise for health reasons and, thereby, are passing the minimum thresholds of health-related physical activity.

According to the WHO's Global Strategy on Diet, Physical Activity, and Health, the recommended levels of physical activity for adults aged 18-64 are as follows:

1. Adults aged 18-64 should do at least 150 minutes of moderate-intensity aerobic physical activity throughout the week or do at least 75 minutes of vigorous-intensity aerobic physical activity throughout the week or an equivalent combination of moderate- and vigorous-intensity activity.

2. Aerobic activity should be performed in bouts of at least ten minutes in duration

3. For additional health benefits, adults should increase their moderate-intensity aerobic physical activity to 300 minutes per week, or engage in 150 minutes of vigorous-intensity aerobic physical activity per week, or an equivalent combination of moderate- and vigorous-intensity activity.

4. Muscle-strengthening activities should be done involving major muscle groups on two or more days a week.

The self-rated health among people with impairments is significantly worse than among people without impairments (Østerlund et al., 2014), and, therefore, it is reasonable to spread health-related initiatives for those with special needs for physical activity and exercise. However, this objective is quite different than that of equality.

When the subject is Sport for All bodies and inclusivity, we have to blur the separation of people with and without impairments and develop a universal approach to sports participation. One step in this direction is to get a fresh look at the data from the survey depicted in Figures 1 and 2.

Although people with impairments are under-represented in sports participation and sports clubs, many people with impairments are in fact active participants in sports and sports clubs in spite of barriers and personal difficulties such as health problems. In total, about 645,000 people with impairments are active in sports and exercise, distributed between 286,000 with physical impairments, 179,000 with physical health problems, and 180,000 with mental health problems. In other words, at least 6-7 persons out of 10 are active in sports and exercise, regardless of their type and degree of impairment.

Likewise, there are about 265,000 people with impairments who are practicing sport in sport clubs, distributed between 122,000 with physical impairments, 74,000 with physical health problems, and 69,000 
with mental health problems. In other words, at least 2-3 persons out of 10 are engaged in sports clubs, regardless of their type and degree of impairment.

Until now, the attention in the Danish sports movement has mainly been limited segregated disability sport under the auspices of the Danish Sport Organization for the Disabled, which has about 12.400 members. However, when people are asked to rate their impairments and sports participation in a broader sense, things look very different. For every person in disability sport clubs, more than 25 persons are integrated or included in mainstream sport clubs; for every person in disability sport clubs, more than 60 persons are participating in sports and exercise.

The human variation and degree of impairments are much greater than what is taken into account in disability sport and, above all, people with impairments should not only be characterized by their impairments. They are people with human rights, just like everyone else. Therefore, we should be aware of the potential stigmatizing and normalizing effects of special needs approaches to sports.

People with and without impairments are different, if not unique, so besides creating equal opportunities for participation in sports, there must be space for diversity and respect for the individual's skills, needs, and interests, regardless of specific impairments and disabilities. A universal approach to sports participation and clubs is much needed, and this will be outlined in the following paragraphs.

\section{The concept of Universal Design}

The concept of Universal Design (UD) was outlined by Maze in 1988: "Universal design is the design of products and environments to be usable by all people, to the greatest extent possible, without the need for adaptation or specialized design" (cit. in Steinfeld \& Maisel, 2012, 28). It emerged from the disability rights movement in the USA in the 1960s, and it has become widely accepted by supranational institutions such as the UN, the WHO, and the Council of Europe.

In the UN's Convention of the Rights of Persons with Disabilities (2006), the scope of UD is extended to programs and services and is a key issue side by side with "discrimination on the basis of disability" and "reasonable accommodation". The WHO (2001) has launched an International Classification of Functioning, Disability, and Health, in which the binary thinking involved in the normal/abnormal attribution to disability is given up in favor of a conception of impairment as a continuous phenomenon. Functioning becomes a matter of being more or less perfect, so that there is a graded scale of functioning, activity, and participation classified by domains and sub-domains. From a Danish point of view, nearby countries like Norway, Germany, and the Netherlands have developed action plans on UD to ensure "equal and democratic rights in society for all individuals, regardless of their age, abilities or cultural background" and are the forerunners in the European context (Ginnerup, 2009, p. 2).

UD is more than spaciousness and equality of access to the environment, which so far is one of the focuses of the Danish Guidelines on Building Regulatives (Hansen, 2012). According to the Center for Universal design in the North Carolina State University the seven Principles of UD are formulated as follows: 
Table 1. Principles of Universal Design

Principle Description

One: Equitable use

Two: Flexibility in use

Three: Simple and intuitive use

Four: Perceptible information

Five: Tolerance for error

Six: Low physical effort

Seven: Size and space for approach and use
The design is useful and marketable to people with diverse abilities.

The design accommodates a wide range of individual preferences and abilities.

Use of the design is easy to understand, regardless of the user's experience, knowledge, language skills, or current concentration level.

The design communicates necessary information effectively to the user, regardless of ambient conditions or the user's sensory abilities.

The design minimizes hazards and the adverse consequences of accidental or unintended actions.

The design can be used efficiently and comfortably and with a minimum of fatigue.

Appropriate use and space is provided for approach, reach, manipulation, and use regardless of user's body size, posture, or mobility.

The Principles of Universal Design were developed in 1997 by a working group of architects, productdesigners, engineers, and environmental design researchers led by Ronald Maze. They gained world-wide attention and significance, but were heavily criticized over the years for lacking clarity of purpose, for not addressing the constraints imposed by context, for a narrow focus on personal empowerment, and for ignoring personalization and customization, which address broader diversity issues and social identity in a more inclusive manner.

Clarifying the specific goals for UD is a useful first step and, therefore, Steinfeld \& Maisel $(2012,90)$ developed eight goals of UD:

Table 2. Goals of Universal Design

Goal Description

One: Body fit

Two: Comfort

Three: Awareness

Four: Understanding

Five: Wellness

Six: Social integration

Seven: Personalization

Eight: Cultural appropriateness
Accommodating a wide range of body size and abilities

Keeping demands within desirable limits of body function

Ensuring that critical information for use is easily perceived

Making methods of operation and use intuitive, clear, and unambiguous

Contributing to health promotion, avoidance of disease, and prevention of injury

Treating all groups with dignity and respect

Incorporating opportunities for choice and the expression of individual preferences

Respecting and reinforcing cultural values and the social and environmental context of any design project 
The concept of UD is related to the construction of built environments and cannot offer the same qualities as nature (Ramsland, 2015, pp. 24-30). Nonetheless, a proposed symbol for UD is very much nature-related, as it is an equal sign superimposed on a blue and green representation of a globe. It was designed for use as a multisensory symbol to identify UD products, facilities, and services (Tauke, 2006).

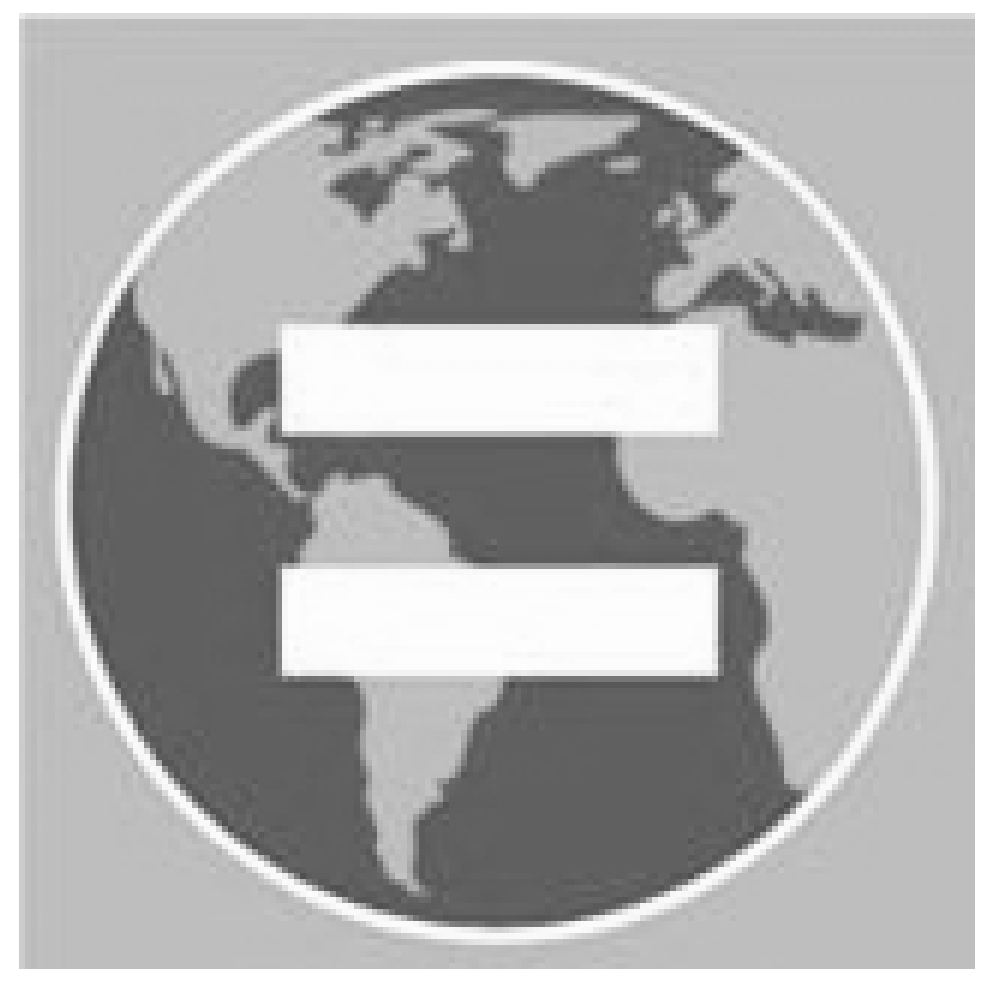

A critical view of the globe reveals a possibly restricted image, since the Eastern world, as well as Australia and other countries, is not represented. UD is certainly devoted to promoting an inclusive society that ensures full equality and participation for all, based upon the Western tradition of Enlightenment which seeks to universalize the human condition (Imrie, 2012, p. 876). It also seems to be part of a search for technological solutions to problems, or, if that is not possible due to impaired conditions of life, it aims to at least ease the way of life for the greatest number of people.

While most of the principles and goals of UD are very useful for the promotion of Sport for All, including the acceptance of a wide range of body sizes and abilities, one of the principles, namely "low physical effort", and one of the goals, namely "comfort", do not fit the traditional values of sport and exercise very well. Therefore, let us finally have a look at Adapted Physical Activity (APA), which for decades has been devoted to promoting sport and exercise for people with special needs, and see how APA is coming to terms with a universal approach.

\section{Adapted Physical Activity}

The International Federation of Adapted Physical Activity (IFAPA) characterizes its focus as individual differences in physical activity and, thereby, aims to highlight diversity. This focus was originally formulated by DePauw and Shirrell (1994), who emphasized individual differences and personenvironmental interactions rather than disabilities. Reid (2003, p. 22) suggested in this vein that APA should be conceptualized as "adaptations that could facilitate physical activity across a wide range of individual differences", and, in addition, it should be characterized by a self-determined involvement in a life span perspective.

With this as a foundation, the IFAPA (2004) decided to delimit the phenomenon of APA as follows: 
"APA is defined as a cross-disciplinary body of knowledge directed toward the identification and solution of individual differences in physical activity. It is a service delivery profession and an academic field of study that supports an attitude of acceptance of individual differences, advocates access to active lifestyles and sport, and promotes innovation and cooperative service delivery programs and empowerment systems. Adapted physical activity includes, but is not limited to, physical education, sport, recreation, dance and creative arts, nutrition, medicine, and rehabilitation".

When stressing and accepting differences among people and not addressing impairments or disabilities at all, the question that arises is this: How can it be that the field of study and professional practices are specialized in all kinds of target groups with special needs? Parasport athletes, people with intellectual disabilities, physical education for people with disabilities, individuals with visual impairments, and students with autism spectrum disorders are groups that are the main focus in the current issue of Adapted Physical Activity Quarterly (2015). While they are all facing the UD principle of "low physical effort" and the associated goal of "comfort" in a demonstrative way, they are also showing their differences in terms of impairments and disabilities.

From one perspective, all people are different. Impairments and disabilities, as well as special needs, are ignored from that perspective. From another perspective, especially in professional practice, people with assigned differences are in focus and, possibly, the stigma associated with the differences in terms of impairments or disabilities is also in focus. Minow (1990, p. 20) formulated the so-called "dilemma of difference" in this way:

"When does treating people differently emphasize their differences and stigmatize or hinder them on that basis? And when does treating people the same become insensitive to their differences and likely to stigmatize or hinder them on that basis?".

But what is a defining difference in the first place? If there are only differences, there are hardly any similarities to be different from. It seems that we also need to relate the differences to what they are, or what they are not. Without concepts of similarity, sameness, and equality, we remain caught in the dilemma of difference.

That is why Zola $(1989,401)$ argued that an exclusively special needs approach to disability is inevitably a short-run approach and suggested that people look towards "the necessary universalizing of a disability policy." We need more universal policies that recognize that the entire population is "at risk" of suffering the aftermath of chronic illness and disability. Without such a perspective, we will further create and perpetuate a segregated, separate but unequal society - a society inappropriate for a larger and older population with "changing needs."

In his assessment, Zola was fully aware of the paradox of the "dilemma of difference" (Goffman, 1964), namely that political demands to end various forms of discrimination require a social analyst to identify those who are experiencing discrimination. Thus, when looking for a potential resolution for the dilemma of difference, we should turn our attention to human rights law and, in particular, to the UN's Convention on the Rights of Persons with Disabilities, including UD, and with a special aim to promote Sport for All.

Most people with impairments practice some kind of adapted sports, exercise, or physical activity in mainstream sports clubs or other non-segregated sports settings and, thereby, are becoming part of communities of practice acknowledging their differences as well as their dignity and rights. A more inclusive Sport for All movement is preferable to segregated or integrated disability sport, provided the persons concerned have a say in every case.

\section{REFERENCES}

Adapted Physical Activity Quarterly (2015). 32(1), ed. by Hutzler, Y.

Claeys, U. (1982). Rationalising Sports Policies. Sport in European Society: A transnational survey into participation and motivation. Strasbourg: Committee for the Development of Sport. 
Coubertin, P. de (1967). The Olympic Idea: Discourses and Essays. Schorndorf near Stuttgart: Verlag Karl Hofmann. Council of Europe (1970). Sport for All: Five countries report. Strasbourg: Committee for the Development of Sport.

Damgaard, M., Steffensen, T. \& Bengtsson, S. (2013). Hverdagsliv og levevilkår for mennesker med funktionsnedscettelse /Everyday life and living conditions for people with impairment/. Copenhagen: SFI - Det Nationale Forskningscenter for Velfærd.

DePauw, K. \& Shirrell, C. (1994). Adapted physical activity: Present and future. Physical Education Review, $17,6-13$. Goffman, E. (1963). Stigma. Notes on the Management of Spoiled Identity. Englewood Cliffs, N.J.: Prentice-Hall Inc.

Hansen, E.J. de P. (2012). Guidelines on Bulding Regulatives 2010. Copenhagen: Statens Byggeforskningsinstitut.

Hansen, J. (2015). The Origin of the Term Handicap in Games and Sports - History of a Concept. Physical Culture and Sport. Studies and Research, 65, 7-13. DOI: 10.1515/pcssr -2015-0006.

Imrie, R. (2012). Universalism, universal design and equitable access to the built environment. Disability \& Rehabilitation, 34(10), 873-882.

International Federation of Adapted Physical Activity (IFAPA: 2004). By Laws. Retrieved March 2, 2015, from http://www.ifapa.biz/imgs/uploads/PDF/IFAPA\%20By-Laws.pdf

Martin, J.J. (2013). Benefits and barriers to physical activity for individuals with disabilities: a social-relational model of disability perspective. Disabil Rehabil, 35(24), 2030-2037.

Minow, M. (1990). Making all the difference: inclusion, exclusion, and American law. Ithaca, N.Y.: Cornell University Press.

Ramsland, L.T. (2015). With Nature and the Outdoors as a Resource: A Case of a One-Footed Elderly Man in a Wheelchair. Physical Culture and Sport Studies and Research, 65, 24-30. DOI: 10.1515/pcssr -2015-0008.

Reid, G. (2003). Defining adapted physical activity. In R.D.Steadward, G.D.Wheeler \& E.J.Watkinson (Eds.), Adapted Physical Activity (pp. 11-25). Edmonton: University of Alberta Press.

Rimmer, J.H., Braddock, D. \& Pitetti, K.H. (1996). Research on physical activity and disability: an emerging national priority. Medicine and science in sports and exercise 28(11), 1366-1372.

Rimmer, J.H., Riley, B., Wang, E., Rauworth, A. \& Jurkowski, J. (2004). Physical activity participation among persons with disabilities. American Journal of Preventive Medicine, 26(5), 419-425.

Sport for Development and Peace International Working Group (2008). Harnessing the Power of Sport for Development and Peace: Recommendations to Governments. Toronto: Right to Play International.

Steinfeld, E. \& Maisel, J.L. (2012). Universal Design: Creating Inclusive Environments. Hoboken, N.J.: John Wiley \& Sons.

Tauke, B. (2006). UDid Universal Design Identity Project. Final Report. Buffalo, N.Y.: IDeA Center.

Tweedy, S.M. \& Vanlandewijk, Y.C. (2011). International Paralympic Committee position stand - background and scientific principles of classification in Paralympic Sport. British Journal of Sports Medicine, 45(4), 259-269.

UNESCO (1978). International Charter of Physical Education and Sport. Paris: UNESCO.

United Nation (2006). Convention on the rights of persons with disabilities. Retrieved March 26, 2015 from http://www.un.org/disabilities/default.asp?id=150

WHO (2004). Global Strategy on Diet, Physical Activity, and Health. Retrieved March 26, 2015, http://www.who.int/dietphysicalactivity/en/

Vonnegut, K. (1961). Harrison Bergeron. Retrieved March 2, 2015, from http://archive.org/stream/HarrisonBergeron/Harrison\%20Bergeron_djvu.txt

Zola, I.K. (1989). Toward the Necessary Universalizing of a Disability Policy. The Milbank Quarterly, 67(Suppl.2, Pt. 2), 401-428.

Østerlund, K., Ryding, K. \& Jespersen, E. (2014). Idrcet, fritid og helbred for mennesker med funktionsnedscttelse /Sports, Leisure, and Health for People with Impairments/. Odense: Center for Handicap og Bevægelse, Syddansk Universitet.

AUTHOR'S ADDRESS:

Ejgil Jespersen

University of Southern Denmark

Institute of Sports Science and Clinical Biomechanics

Campusvej 55

DK-5230 Odense M ,Denmark

Email: ejjespersen@health.sdu.dk 